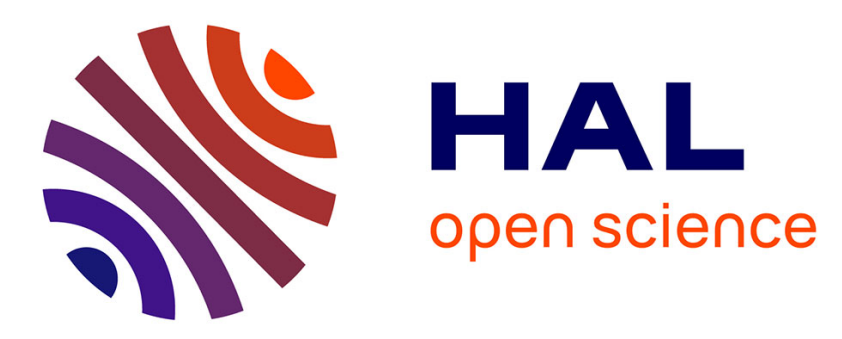

\title{
In situ magnetic resonance imaging study of the impregnation of gamma-alumina pellets
}

A. Nowacka, J. Moughames, Z. Adem, Anne-Agathe Quoineaud, Matthieu Rolland, F. Guenneau, A. Gedeon

\section{- To cite this version:}

A. Nowacka, J. Moughames, Z. Adem, Anne-Agathe Quoineaud, Matthieu Rolland, et al.. In situ magnetic resonance imaging study of the impregnation of gamma-alumina pellets. Applied Catalysis A : General, 2015, 503, pp.111-116. 10.1016/j.apcata.2015.07.014 . hal-01256410

\section{HAL Id: hal-01256410 https://hal.science/hal-01256410}

Submitted on 21 Nov 2018

HAL is a multi-disciplinary open access archive for the deposit and dissemination of scientific research documents, whether they are published or not. The documents may come from teaching and research institutions in France or abroad, or from public or private research centers.
L'archive ouverte pluridisciplinaire HAL, est destinée au dépôt et à la diffusion de documents scientifiques de niveau recherche, publiés ou non, émanant des établissements d'enseignement et de recherche français ou étrangers, des laboratoires publics ou privés. 
$0.05 \mathrm{M}$ $\mathrm{Ni}^{2+}$
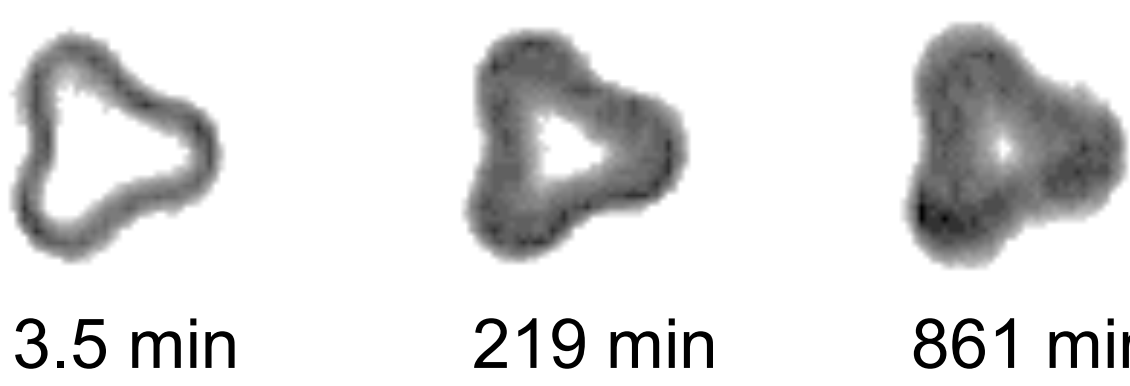

219 min

861 min

1972 min
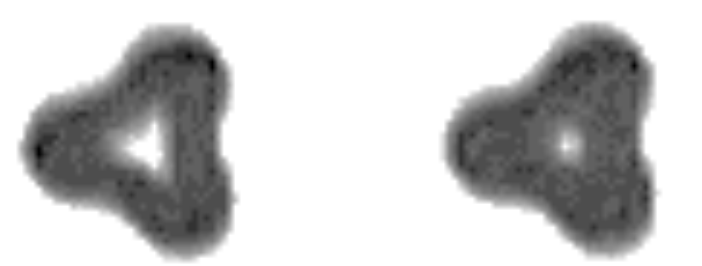

$2.6 \mathrm{~min}$

$5.3 \mathrm{~min}$

$9.5 \mathrm{~min}$

$15 \min$

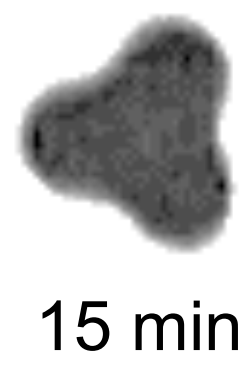




\section{Highlights}

SPI enables studying catalyst preparation in the presence of paramagnetic ions.

The transport rate of ions in the pellet depends non-linearly on the concentration.

A minimum $\mathrm{Ni}^{2+}$ concentration is required to quickly reach uniform ion distribution. 


\title{
In situ Magnetic Resonance Imaging study of the impregnation of $\gamma$-alumina pellets
}

\author{
A. Nowacka ${ }^{1}$, J. Moughames ${ }^{1}$, Z. Adem ${ }^{2}$, A.-A. Quoineaud ${ }^{3}$, M. Rolland ${ }^{3}$, F. Guenneau ${ }^{1}$, A. Gédéon ${ }^{1}$ \\ ${ }^{1}$ Sorbonne Universités, UPMC Univ Paris 06, CNRS, Collège de France, Laboratoire de Chimie de la \\ Matière Condensée de Paris, 11 place Marcelin Berthelot, 75005 Paris, France \\ ${ }^{2}$ Lebanese University, Faculty of Science, Branch II, Department of Physics, Fanar, Lebanon \\ ${ }^{3}$ IFP Energies nouvelles, Etablissement de Lyon, Rond-point de l'échangeur de Solaize BP3, 69360 \\ Solaize, France \\ *corresponding authors: agnieszka.nowacka@upmc.fr, flavien.guenneau@upmc.fr
}

\begin{abstract}
In petroleum refining, $\gamma$-alumina is used as a solid support of molybdenum nickel/cobalt promoted catalysts for the hydrotreatment processes, such as hydrodesulfurization. The ever decreasing norms for the sulfur content in gasoline require better and more efficient catalysis, prompting extensive research on the materials and the factors influencing the activity, selectivity and stability of the catalytic processes. In the present study, Magnetic Resonance Imaging Single Point Imaging is tested as a tool to monitor the impregnation of $\gamma$-alumina pellets with $\mathrm{Ni}\left(\mathrm{NO}_{3}\right)_{2}$ aqueous solutions at varying $\mathrm{Ni}^{2+}$ concentration. The method enables a study in the presence of paramagnetic elements in the alumina support, in the conditions of very fast $T_{1}$ and $T_{2}$. It is shown that at higher concentrations of metal ions a homogenous distribution in the support is attained faster. A non-linear dependence is observed and a minimum ion concentration of $0.2 \mathrm{M}$ is necessary for achieving short impregnation times of alumina pellets of millimeter size scale.
\end{abstract}

Keywords: $\mathrm{MRI}, \mathrm{SPI}, \gamma-\mathrm{Al}_{2} \mathrm{O}_{3}$, alumina impregnation, catalyst preparation, $\mathrm{Ni}^{2+}$

\section{Introduction}

The removal of sulfur from diesel fractions is receiving increasing interest due to the environmental legislation enforcing the reduction of sulfur content in fuel. Since 2009, regulations required the sulfur content in diesel fractions to be lower than $10 \mathrm{ppm}$ in Europe [1] and the "ultra low sulfur diesel" objective is now being considered. In order to face those demanding, environmental standards, the development of more active and selective hydrodesulfurization (HDS) catalysts is desired, to improve fuel quality without negative impact on the purification cost.

Due to its high specific surface area, mechanical, chemical and thermal stability [2], the aluminum oxide $\left(\gamma-\mathrm{Al}_{2} \mathrm{O}_{3}\right)$, also called $\gamma$-alumina, is widely used as a solid support for catalysts in numerous industrial processes. Cobalt or nickel-promoted molybdenum sulfide catalysts are used as the active phase, called CoMoS or NiMoS, in hydrotreatment processes, such as HDS, due to their high activity and stability. The CoMoS and NiMoS phases are obtained by sulfidation of the oxide catalysts. However, when supported on $\gamma$-alumina, $\mathrm{Ni}$ or Co-promoted $\mathrm{MoS}_{2}$ catalysts are composed of several other less active species such as unpromoted $\mathrm{MoS}_{2}$ particles, NiS or $\mathrm{Co}_{9} \mathrm{~S}_{8}$ clusters, $\mathrm{Ni}^{2+}$ or $\mathrm{Co}^{2+}$ in $\mathrm{Al}_{2} \mathrm{O}_{3}$ (nickel or cobalt aluminates, respectively), and Mo oxysulfides [3,4]. The preparation method is crucial to improve the promotion of $\mathrm{Mo}$ and decrease the formation of the unpromoted species.

Effort has been put into investigating the efficiency of the catalysis [5-7] and analyzing the factors influencing the catalyst preparation, such as $\mathrm{pH}[8,9]$ or the presence of complexing agents [10]. Highly active catalysts were obtained by modifying the sulfidation procedure [11], using carriers other than alumina [12-14], employing various precursors, such as thiometallates [15], carbonyl complexes [16], heteropolyanions [17] or even additives such as chelating agents $[18,19]$. Furthermore, the physicochemical properties of the $\gamma$-alumina support itself were studied [20], as well as those of the active species during the impregnation process [21-23]. 
Among the experimental techniques that can be used to characterize the impregnation process, Nuclear Magnetic Resonance (NMR) and Magnetic Resonance Imaging (MRI) provide a unique, nondestructive method of studying materials and processes in situ. The phenomenon of magnetic resonance (MR) is based on the presence of nuclear isotopes, such as ${ }^{1} \mathrm{H},{ }^{13} \mathrm{C},{ }^{27} \mathrm{Al}$, which respond to a strong, external magnetic field [24]. The response is dependent on a number of parameters, allowing the observer to distinguish between the nuclei experiencing microenvironments different in terms of chemical composition or mobility, via the means of chemical shift or relaxation phenomena, respectively [24]. Thus, placing an (impregnated) alumina support in a magnetic field, it is possible to use the atomic nuclei present in the catalyst components themselves for the study. The nondestructive aspect of the method permits taking consecutive measurements to investigate dynamic processes, such as ion diffusion within an alumina extrudate.

NMR spectroscopy, especially under the conditions of Magic Angle Spinning, has been extensively used to study catalysts and catalysis [25-27], offering solutions for in situ observation in batch-like [28] and flow [29] conditions. Magnetic Resonance ${ }^{1} \mathrm{H}$ Imaging $\left({ }^{1} \mathrm{H}\right.$ MRI) is becoming an increasingly popular technique, allowing for 2- and 3-dimensional imaging of the liquid components within the catalyst in order to not only identify the molecular species but also to map out their positions in the solid support. Thus the impregnation of the catalyst support with metal ions [30,31], as well as the flow of liquid/gas in a working trickle-bed catalyst [32], can be visualized in situ. Simultaneously, attempts have been made to analyze the structure of the alumina support itself, with the use of multinuclear solid-state MRI [33].

In the present study, we investigate the first step of the catalyst preparation: the impregnation of the alumina support with a metal salt solution. In order to ensure efficient HDS, the active phase should be homogeneously distributed throughout the pellet volume. Simultaneously, factors such as the time necessary for obtaining homogeneous ion distribution and the ion concentration that can be introduced into the pellet porosity come into play. In this article we propose an MRI-based method for estimating the first of those factors at a range of $\mathrm{Ni}^{2+}$ concentrations. The aim is not to quantitatively describe the concentration profile during the impregnation, but to discuss the influence of the solution concentration on the time required for reaching a uniform ion distribution.

Due to water ${ }^{1} \mathrm{H}$ interactions with the porous material surface, as well as the traces of paramagnetic elements present in the alumina, the transverse relaxation time $\left(T_{2}\right)$ of pure water inside the alumina is reduced to values of the order of a couple of milliseconds. Such a short $T_{2}$ excludes the possibility of using the widely-spread spin echo based sequences [30,31,34-37], which usually require a couple of milliseconds of preparation time and gradient encoding. A similar problem existing in the field of medical imaging, special spin echo sequences, using ultrashort echo time [38] or even zero echo time [39] have been designed, exploiting radial sampling schemes to reduce the necessary echo time. A considerable drawback, in case of studies of dynamic processes, relies in the an increased number of acquisitions [38], which leads to longer experimental times.

There also exist pulse sequences designed to study paramagnetic samples with MRI, the most notable being continuous wave MRI $[40,41]$ and Constant-Time Imaging, CTI $[42,43]$, also known as Single Point Imaging (SPI). Both have been successfully used on bentonite [40,43], a clay where transverse relaxation times of the order of milliseconds can be expected, due to the presence of paramagnetic nuclei.

Because continuous wave MRI requires considerable hardware adjustments, we propose SPI as a tool to follow the impregnation of $\gamma-\mathrm{Al}_{2} \mathrm{O}_{3}$ pellets with $\mathrm{Ni}\left(\mathrm{NO}_{3}\right)_{2}$ solutions of varying concentration. Designed for studying materials with short $\mathrm{T}_{2}$ values, SPI is based on simultaneous switching on of all three gradients prior to the excitation pulse, decreasing the required preparation time. It thus makes SPI an ideal tool for studying the impregnation of alumina pellets with traces of paramagnetic elements in situ.

\section{Materials and Methods}




\section{Alumina pellet impregnation}

Trilobe pellets of $\gamma$-alumina with 1.2-1.4 mm diameter and 5-6 mm length were prepared by kneading-extrusion of boehmite powder. $\mathrm{Hg}$ porosimetry (Micromeritics Autopore IV) and $\mathrm{N}_{2}$ isotherm (Micromeritics ASAP 2420) were used to determine the specific surface area, porosity and mean pore size of the alumina to be $200-250 \mathrm{~m}^{2} \mathrm{~g}^{-1}, 0.7-0.9 \mathrm{~mL} \mathrm{~g}^{-1}$ and $8-11 \mathrm{~nm}$, respectively. The point of zero charge (pzc) was 8 - 8.5. The alumina pellets were not submitted to any pre-treatment before impregnation. $\mathrm{Ni}\left(\mathrm{NO}_{3}\right)_{2} \cdot 6 \mathrm{H}_{2} \mathrm{O}$ of $\geq 98.5 \%$ purity (Sigma-Aldrich, CAS number 13478-00-7) was used to prepare solutions at the desired concentrations of $\mathrm{Ni}^{2+}$ ions: $0.05 \mathrm{M}, 0.1 \mathrm{M}, 0.2 \mathrm{M}$ and $0.3 \mathrm{M}$. The $\mathrm{pH}$ of the prepared solutions varied from 6 to 5.1 .

Impregnation was conducted by rapidly submerging a semi-dry alumina pellet in a $\mathrm{Ni}\left(\mathrm{NO}_{3}\right)_{2}$ aqueous solution of chosen concentration for $30 \mathrm{~s}$. The pellet was then taken out and the excess solution was removed by absorbing paper. The pellet was subsequently transferred into a $5 \mathrm{~mm}$, thick-wall NMR tube having the internal diameter of $2.2 \mathrm{~mm}$. Throughout the article, the samples will be referred to by the $\mathrm{Ni}^{2+}$ concentration of the impregnating solution. After the MRI experiments, the samples were controlled with an electron microprobe (Jeol 8100 Electron Probe Micro Analyser with an EDS detector) to confirm the homogeneous ion distribution.

$M R I$

All experiments were performed at ambient temperature, on a Bruker Avance $300 \mathrm{MHz}(7 \mathrm{~T})$ magnet, equipped with a $5 \mathrm{~mm}$ micro imaging probe, having the maximum gradient capacity of $2 \mathrm{~T} \mathrm{~m}^{-1}$ in the $x, y$ and $z$ directions. The SPI pulse sequence was used with a field of view (FOV) of $2.5 \times 2.5 \times 8 \mathrm{~mm}$ and $32 \times 32 \times 8$ acquisition points, resulting in the voxel size of $0.078 \times 0.078 \times 1 \mathrm{~mm}$. The gradient encoding time, $T_{P}$, was set to $100 \mu \mathrm{s}$ with a maximum gradient of $1.4 \mathrm{~T} \mathrm{~m}^{-1}$ in $\mathrm{x}$ and $\mathrm{y}$ directions and $0.11 \mathrm{~T} \mathrm{~m}^{-1}$ in the $z$ direction. An excitation pulse of $90^{\circ}$ and $15 \mu \mathrm{s}$ was used. With the recycle delay, $T_{R}$, of $5 \mathrm{~ms}$ and one repetition per point the total experimental time of $41 \mathrm{~s}$ was achieved.

As stipulated in the original CTI article [42], the use of long excitation pulse can lead to the blurring of sharp edges in the image and the loss of resolution. To preserve the image quality the pulse duration, $T_{\text {pul, }}$ must satisfy:

$$
T_{p u l} \leq \frac{2 T_{p}}{n}
$$

where $n$ is the number of points in the k-space. For the experimental parameters chosen in this study, $T_{p}=100 \mu \mathrm{s}$ and $n=32$ in $\mathrm{x}$ and y directions, the maximum pulse duration is recommended to be $6.25 \mu \mathrm{s}$. However, the blurring effect was investigated experimentally and found to be unobservable on the images. In the $z$ direction, where $n=8$, the maximum recommended pulse duration is $25 \mu \mathrm{s}$.

Inversion recovery and CPMG pulse sequences were used to measure the $T_{1}$ and $T_{2}$ relaxation times, respectively. The $180^{\circ}$ pulse was set to $30 \mu \mathrm{s}$ and the echo time was $400 \mu \mathrm{s}$. The measurements were made after homogenous ion distribution was obtained.

\section{Image analysis}

An automated procedure was implemented in the Halcon HDevelop image treatment environment to refine the image analysis. In each image (Figure 1a), the ion-rich, bright zone of the pellet was identified by choosing an appropriate threshold (Figure 1b). Subsequently, the unphysical dents and protrusions at the interface were removed (Figure 1c). The radius and the position of the smallest circle encompassing the extrudate were identified (Figure 1d). The value of pixel intensity at the pellet core was measured by taking the minimum value of the 4 pixels adjacent to the center of the circle (Figure 1e). 


\section{Results and discussion}

As mentioned in the introduction, short transverse relaxation times exclude the use of traditional, spin-echo based imaging pulse sequences. Requirements of pulse length and gradient encoding time, as well as the delays necessary for correct functioning of the spectrometer, set the lower limit of the time required between the excitation pulse and the acquisition at values comparable to or higher than the $T_{2}$ of water ${ }^{1} \mathrm{H}$ in our alumina pellets (Table 1 ). In practice, the $T_{2}$ of the order of a couple of milliseconds leads to nearly complete signal decay before the end of the pulse sequence and gradient encoding, even in the absence of the paramagnetic, metal ions purposefully introduced into the pellet as the catalyst precursors.

Single Point Imaging (SPI) is an MRI technique originally designed to study solid-state samples with short transverse relaxation times [42]. Rather than relying on echo techniques, SPI encodes the spatial coordinates by the use of three, simultaneous phase gradients (Figure 2). The gradients are switched on before the excitation pulse, decreasing the evolution period to the values of the order of hundreds of microseconds. Such an approach allows the acquisition of fast-relaxing signal components.

However, the acquisition of a single k-point per excitation results in the increase of the experimental time due to the recycle delay, necessary for complete longitudinal relaxation (related to $T_{1}$ ) after each acquisition. Two options can be used to shorten the recycle delay: using a small-angle excitation pulse or allowing $T_{1}$ contrast to be introduced into the image. In the current study, the excitation pulse flip angle and the recycle delay were set to $90^{\circ}$ and $5 \mathrm{~ms}$, respectively, in order to obtain the strongest $\mathrm{T}_{1}$ contrast possible.

In the absence of nickel the water protons $\left({ }^{1} \mathrm{H}\right)$ experience $\mathrm{T}_{1}$ of the order of hundreds of milliseconds (Table 1), due to the paramagnetic elements present in the solid support. The presence of nickel ions decreases the $\mathrm{T}_{1}$ of water ${ }^{1} \mathrm{H}$ to $19 \mathrm{~ms}$, at the lowest investigated concentration, $0.05 \mathrm{M}$. In a sense, the nickel ions act as a contrast agent, allowing the observation of the water ${ }^{1} \mathrm{H}$ signal in their proximity, while the water ${ }^{1} \mathrm{H}$ signal in other microenvironments is efficiently cancelled, as has been verified by recording images of an alumina pellet impregnated with pure water.

The use of a long excitation pulse simultaneously to the incremented magnetic field gradients raises the question of insufficient edge definition because the magnetization corresponding to high k-space values might get attenuated [42]. Indeed, according to Equation 1, the used pulse length, $T_{\text {pul }}=15 \mu \mathrm{s}$, is longer than recommended. To verify the correctness of the proposed set up, an experiment was conducted with $T_{\text {pul }}=5 \mu \mathrm{s}$, well below the limit set by Equation 1. No difference between the images recorded with $T_{p u l}=15 \mu \mathrm{s}$ and $T_{p u l}=5 \mu \mathrm{s}$ was observed. It can be explained by the irregular shape of the alumina pellet and a relatively low resolution of the image, compared to the size of the pellet: a pixel on the image corresponds to $0.078 \times 0.078 \mathrm{~mm}$, while the pellet diameter is $1.2-1.4 \mathrm{~mm}$. Conversely, a significant amount of signal from the microenvironments not containing nickel ions was present in the images recorded with the $T_{p u l}=5 \mu \mathrm{s}$ excitation pulse, decreasing the image contrast.

The current study deals with dynamic phenomena and a minimal total acquisition time was required, with the best possible contrast and SNR. Furthermore, the estimation of uniform distribution in the extrudate was made based on the signal in the centre of the pellet reaching equilibrium, which would be minimally affected by edge blurring. Consequently we have chosen to keep the $90^{\circ}$ excitation pulse.

Figure 3 shows the results of the analysis conducted with Halcon HDevelop (Figure 1) for a series of experiments following the ion penetration of $\mathrm{Ni}^{2+}$ at $0.1 \mathrm{M}$ impregnating solution. Each point corresponds to the signal intensity of a pixel in the middle of the extrudate, averaged over $1 \mathrm{~mm}$ thickness in the $z$ direction. Images one and eight were empty in this case, due to the length of the pellet.

For the first 50 minutes there is no change in signal intensity, after which a slope appears, leading to equilibrium at approximately $200 \mathrm{~min}$. This trend is the same in all four inner images, plotted on Figure 3 in green and black. The edge images barely show a change of intensity, starting from a value 
nearly $30 \%$ higher than the inner images. While initially surprising, it can be explained by the impregnation method we used, which implies that the $\mathrm{Ni}^{2+}$ ions enter into the pellet by the sides, the top and the bottom. The ions entering through the top and the bottom influence the signal in the middle of the edge images even at short times. Concurrently, we observe lower equilibrium intensity for the external slices, due to the pellet placement, illustrated on the legend of Figure 3 . The space represented by the edge images does not contain a full $1 \mathrm{~mm}$ thickness of the alumina extrudate.

The issues, of the top/bottom ion penetration and the pellet positioning in the magnet, become irrelevant if either of the two innermost images, namely four or five on Figure 3, are used for data analysis. Not only do they always contain a full $1 \mathrm{~mm}$ of pellet in the $z$ direction, but also they are more than $1 \mathrm{~mm}$ away from the top and the bottom of the pellet. Considering homogenous ion penetration from all sides, as alumina structure has no preferential direction, the influence of top and bottom ion penetration is limited to distances smaller than half the pellet radius, $0.6-0.7 \mathrm{~mm}$, after which the ions should reach uniform distribution throughout the pellet. Consequently, the innermost images are considered henceforth, precluding the influence of the pellet length and exact position on the measurement results.

Images, representing an average over $1 \mathrm{~mm}$ thickness in the middle of the extrudates are shown in Figure 4. The ${ }^{1} \mathrm{H}$ signal, which appears as the light grey areas, is only observed in the presence of $\mathrm{Ni}^{2+}$ ions, providing a fast, visual estimation of the progress of ion penetration into the solid support. While water molecules penetrate into the core of the pellet immediately, as verified by conventional spin echo imaging, the ${ }^{1} \mathrm{H}$ signal in the leftmost images in Figure 4, recorded within the first $3 \mathrm{~min}$ of ion diffusion, is only visible at the edges of the pellets. The paramagnetic ions are located close to the edge of the pellet, forming a band of a width increasing with increasing ion concentration of the impregnating solution.

Signal intensity of the middle pixel, normalized to the maximum of each series, is also shown in Figure 4. As time elapses, the ions penetrate further in, until the appearance of uniform ion distribution throughout the pellet, leading to the homogenous signal observed on the rightmost images in Figure 4. The ion penetration into the pellet is accompanied by signal intensity increase in the middle pixel, until an equilibrium value. While the signal intensity is related to the ion concentration, this relation is neither linear nor trivial. No concentration information is immediately accessible from the signal intensity.

The impregnation appears to be roughly symmetric, as can be expected from a material that is homogeneous on the scale of the voxel size. The shape of the bright band on the images changes with the ion diffusion time. At the early stage, the band mimics the trilobe shape of the extrudate, however, the penetration from two sides in the lobe leads to a simpler, triangular and circular shape of the inner edge of the band. Irregularities, such as in the beginning of the $0.05 \mathrm{M}$ series (see the top lobe of the pellet in Figure 4), can be explained by the presence of preferential diffusion directions present in some extrudates.

The case of the alumina extrudate impregnated with the $0.3 \mathrm{M}$ solution is exceptional. Already at the first measurement, recorded at $1.6 \mathrm{~min}$ from the beginning of the immersion in the $\mathrm{Ni}\left(\mathrm{NO}_{3}\right)_{2}$ solution, a homogeneous ion distribution throughout the pellet is observed. Due to the sample preparation procedure and the acquisition parameters, it is impossible to reduce the time between the immersion and the first measurement.

The time necessary for achieving homogenous ion distribution is estimated in Figure 4. Equilibrium intensity for each series was set to the average value of the last eight measurements, where the signal has reached a plateau (see horizontal lines in Figure 4). The slope of increasing signal intensity was drawn as a guide to the eye. The first image recorded with fully uniform signal (rightmost in Figure 4) was decided to be at or after the intersection of the equilibrium intensity line and the slope.

The time of the appearance of homogeneous ion distribution, expressed in minutes from the beginning of the immersion, is plotted in Figure 5, with $0.3 \mathrm{M}$ assumed at the time of the first 
measurement. A non-linear dependence on the concentration can be seen. Indeed a roughly ten-fold time decrease from concentration to concentration is observed (Table 2).

The solutions' pH being lower than the alumina pzc, it renders the alumina surface positively charged, repulsing the ions and facilitating their passage into the pellet. Decreasing the $\mathrm{pH}$ with increasing ion concentration will increase the positive charge of the alumina, enhancing this effect. Additionally, higher ion concentration entails higher diffusion driving force. Both mechanisms will decrease the time required to achieve uniform distribution, when millimeter-size pellets are used.

Whereas it is not trivial to quantify the influence of those two mechanisms, as well as van der Waals interactions or covalent binding of ions to the surface, the findings presented in this paper are of important consequence in the preparation of catalysts. While homogeneous impregnation can be achieved with salt solutions of as little concentration as $0.05 \mathrm{M}$, it is clearly convenient to increase the concentration to $0.2 \mathrm{M}$, for the homogenous ion concentration to occur in a time of the order of minutes: the timescale of large-volume impregnation. Because the ion concentrations used in the HDS catalysts are higher than $0.3 \mathrm{M}$ no additional waiting time for homogeneous impregnation is necessary in the catalyst preparation process.

To our knowledge no complete investigation following the ion penetration into the pellet, at different ion concentrations, has been conducted. Few studies of the duration of the impregnation process in general are found in the literature [30] and among them, the impregnation of a $3.85 \mathrm{~mm}$ diameter alumina pellet with $\mathrm{Ni}^{2+}$ at the concentration of $0.5 \mathrm{M}$ [31]. Authors report complete penetration of the pellet with the ions within $30 \mathrm{~min}$ and fully homogenous impregnation in an hour. However, already at 5 min of the impregnation time, a band comparable to our sample's diameter is homogeneously impregnated, insofar as can be deduced from the images.

Our results remain in satisfactory agreement with the study of Espinosa-Alonso et al. Although we expect slightly faster ion penetration at the $\mathrm{Ni}^{2+}$ concentration of $0.5 \mathrm{M}$, the use of different alumina support prevents a thorough comparison of both experiments. The influence of the impregnation method also remains an open question as immersing an extrudate in a salt solution leaves little control over the amount of ions introduced into the solid support.

A systematic study of pellets with different specific surface areas and with different immersion times could shed light on this issue. However, it is beyond the scope of the current study, which should be considered as a proof of concept. It must be added that the sample preparation with calculated solution content would be impractical in the case of pellets as small as $1.2 \mathrm{~mm}$ diameter and a couple of millimeters long. The solution volume necessary to fill the entirety of the pores in such a pellet is of the order of microliters, making a homogeneous impregnation difficult to achieve at timescales allowing in situ visualization of ion diffusion.

\section{Conclusions}

We have successfully used a solid state MRI pulse sequence, Single Point Imaging (SPI) for recording the signal of the water ${ }^{1} \mathrm{H}$ in the presence of paramagnetic elements. Although the experimental times are longer than for spin echo based sequences at equivalent image resolution, such an approach opens the possibilities for studying catalyst preparation in cases of fast relaxing NMR signal. It also shows that $T_{1}$ contrast can be used equivalently to $T_{2}$ contrast for differentiating between the environments with and without the impregnating, paramagnetic ions, such as $\mathrm{Ni}^{2+}$ and $\mathrm{Co}^{2+}$.

The obtained results show that already at a concentration as low as $0.05 \mathrm{M} \mathrm{Ni}^{2+}$ a homogeneous ion distribution can be achieved in an alumina support with a high specific surface area and porous volume. However, in terms of HDS catalyst preparation, it is advantageous to reach homogeneous ion distribution times shorter than the duration of the impregnation process. Here, for the $1.2 \mathrm{~mm}$ diameter and 5-6 mm length pellets used, such short time was reached already at the concentration of $0.2 \mathrm{M} \mathrm{Ni}^{2+}$. Further increasing the ion concentration leads to nearly instantaneous, homogeneous 
ion distribution. Consequently, in catalyst preparation, where the concentrations higher than $0.3 \mathrm{M}$ are used, no question of homogeneity needs to be posed.

\section{Acknowledgements}

This work was supported by French state funds managed by the ANR within the Investissements d'Avenir programme under reference ANR-11-IDEX-0004-02, and more specifically within the framework of the Cluster of Excellence MATISSE led by Sorbonne Universités. Franck Launay is acknowledged for fruitful discussions. 


\section{Tables and figure captions}

Table 1 The $\mathrm{T}_{1}$ and $\mathrm{T}_{2}$ values for water ${ }^{1} \mathrm{H}$ nuclei, observed in the $\gamma$-alumina pellets at different $\mathrm{Ni}^{2+}$ concentrations of the impregnating solution. The measurements were made on homogeneously impregnated pellets.

\begin{tabular}{c|c|c}
$\mathrm{Ni}^{2+}(\mathrm{M})$ & $\mathrm{T}_{1}(\mathrm{~ms})$ & $\mathrm{T}_{2}(\mathrm{~ms})$ \\
\hline 0 & 344 & 2.6 \\
\hline 0.05 & 19 & 2 \\
\hline 0.1 & 10.3 & 1.45 \\
\hline 0.2 & 6.6 & 1 \\
\hline 0.3 & 3.9 & 0.73
\end{tabular}

Table 2 The time, in minutes, required for obtaining a homogeneous ion distribution throughout the pellet for the concentrations investigated. *time of the first measurement, showing homogeneous ion distribution

\begin{tabular}{c|c|c|c|c}
$\mathrm{Ni}^{2+}(\mathrm{M})$ & 0.05 & 0.1 & 0.2 & 0.3 \\
\hline Time (min) & 1972 & 186 & 15 & $1.6^{*}$
\end{tabular}

Figure 1 Images illustrating the steps of the analysis performed in Halcon HDevelop: a) a raw image obtained from the spectrometer; b) choosing a threshold to discriminate the signal from noise; c) removing the unphysical dents on the pellet surface; d) finding the smallest circle encompassing the pellet; e) finding the 4-pixel middle of the circle, from which the minimum will be chosen to estimate the signal intensity.

Figure 2 Single Point Imaging (SPI) pulse sequence. All three gradients (grad) are applied prior to the $90^{\circ}$ radio frequency (RF) pulse. A single point is acquired after a constant gradient encoding time $T_{p}$, marked by a circle. The sequence is repeated, with the repetition time $T_{R}$, for the number of times equivalent to the number of points.

Figure 3 Relative signal intensity in the center of the pellet, normalized to the maximum intensity value of the whole dataset, presented as a function of ion diffusion time, for an alumina pellet impregnated with $0.1 \mathrm{M} \mathrm{Ni}^{2+}$. The results from the edge images are plotted in red, the middle images in green and the innermost images in black (images 1 and 8 were empty in this case). A schematic drawing of the pellet positioning relative to the image definitions is included with the legend.

Figure 4 Relative signal intensity, normalized for each series, in the center of the pellet as a function of ion diffusion time. The concentration on the left indicates the $\mathrm{Ni}^{2+}$ solution in which the pellet was impregnated. The images corresponding to $1 \mathrm{~mm}$ pellet thickness in the middle of the pellet, rescaled for the sake of presentation, show the progression of ions inside the pellet. The images were recorded at the times marked with squares on the relative intensity graphs. The 
horizontal lines on the relative intensity graphs indicate the signal intensity at equilibrium, set to the average of the eight last measurements in each series. A guide to the eye for the slope of increasing signal intensity is added in each series. The appearance of homogeneous distribution was estimated to be at the intersection of the equilibrium intensity line and the slope of increasing intensity. The values are: $1972 \mathrm{~min}$ for the $0.05 \mathrm{M}, 186 \mathrm{~min}$ for $0.1 \mathrm{M}$ and $15 \mathrm{~min}$ for $0.2 \mathrm{M}$ sample.

Figure 5 Time necessary to achieve a homogeneous ion distribution, in minutes, as a function of ion concentration of the impregnating solution. The values for $0.05,0.1$ and $0.2 \mathrm{M}$ were taken from the estimation presented in Figure 4 , while the value for $0.3 \mathrm{M}$ is the time of the first image: $1.6 \mathrm{~min}$. 


\section{References}

[1] Off. J. Eur. Union L76 (2003) pp. 10.

[2] C. Misra, Industrial Alumina Catalysts, ACS Monograph, 1986.

[3] H. Topsøe, B.S. Clausen, F.E. Massoth, in:, Hydrotreating Catal. - Sci. Technol., 1996, pp. 1-269.

[4] H. Toulhoat, P. Raybaud, Catalysis by Transition Metal Sulphides from Molecular Theory to Industrial Application, Technip, 2013.

[5] D.H. Broderick, B.C. Gates, AIChE J. 27 (1981) pp. 663-673.

[6] M. Egorova, R. Prins, J. Catal. 225 (2004) pp. 417-427.

[7] U.S. Ozkan, L.P. Zhang, S.Y. Ni, E. Moctezuma, J. Catal. 148 (1994) pp. 181-193.

[8] J. Cruz, M. Avalos-Borja, R. López Cordero, M.A. Bañares, J.L.G. Fierro, J.M. Palacios, A. López Agudo, Appl. Catal. Gen. 224 (2002) pp. 97-110.

[9] J.H.A. Martens, R. Prins, Appl. Catal. 46 (1989) pp. 31-44.

[10] K. Al-Dalama, B. Aravind, A. Stanislaus, Appl. Catal. Gen. 296 (2005) pp. 49-53.

[11] R.P. Silvy, P. Grange, F. Delannay, B. Delmon, Appl. Catal. 46 (1989) pp. 113-129.

[12] M. Breysse, J.L. Portefaix, M. Vrinat, Catal. Today 10 (1991) pp. 489-505.

[13] T. Klimova, M. Calderón, J. Ramírez, Appl. Catal. Gen. 240 (2003) pp. 29-40.

[14] Y. Okamoto, K. Ochiai, M. Kawano, K. Kobayashi, T. Kubota, Appl. Catal. Gen. 226 (2002) pp. 115-127.

[15] W. Eltzner, M. Breysse, M. Lacroix, M. Vrinat, Polyhedron 5 (1986) pp. 203-210.

[16] F. Maugé, A. Vallet, J. Bachelier, J.C. Duchet, J.C. Lavalley, J. Catal. 162 (1996) pp. 88-95.

[17] C. Martin, C. Lamonier, M. Fournier, O. Mentré, V. Harlé, D. Guillaume, E. Payen, Inorg. Chem. 43 (2004) pp. 46364644.

[18] M.A. Lélias, P.J. Kooyman, L. Mariey, L. Oliviero, A. Travert, J. van Gestel, J.A.R. van Veen, F. Maugé, J. Catal. 267 (2009) pp. 14-23.

[19] T. Shimizu, K. Hiroshima, T. Honma, T. Mochizuki, M. Yamada, Catal. Today 45 (1998) pp. 271-276.

[20] X. Yang, Z. Sun, D. Wang, W. Forsling, J. Colloid Interface Sci. 308 (2007) pp. 395-404.

[21] J.A. Bergwerff, T. Visser, G. Leliveld, B.D. Rossenaar, K.P. de Jong, B.M. Weckhuysen, J. Am. Chem. Soc. 126 (2004) pp. 14548-14556.

[22] E.K. Gibson, M.W. Zandbergen, S.D.M. Jacques, C. Biao, R.J. Cernik, M.G. O’Brien, M. Di Michiel, B.M. Weckhuysen, A.M. Beale, ACS Catal. 3 (2013) pp. 339-347.

[23] M.W. Zandbergen, S.D.M. Jacques, B.M. Weckhuysen, A.M. Beale, Angew. Chem. Int. Ed. 51 (2012) pp. 957-960.

[24] J. Keeler, Understanding NMR Spectroscopy, 2nd Edition, Wiley, Cambridge, 2010.

[25] I.I. Ivanova, Y.G. Kolyagin, Chem. Soc. Rev. 39 (2010) pp. 5018-5050.

[26] W. Zhang, S. Xu, X. Han, X. Bao, Chem. Soc. Rev. 41 (2012) pp. 192-210.

[27] D.C. Roe, P.M. Kating, P.J. Krusic, B.E. Smart, Top. Catal. 5 (1998) pp. 133-147.

[28] A.G. Stepanov, V.N. Parmon, D. Freude, Kinet. Catal. 48 (2007) pp. 521-534.

[29] M. Hunger, Prog. Nucl. Magn. Reson. Spectrosc. 53 (2008) pp. 105-127.

[30] A.A. Lysova, J.A. Bergwerff, L. Espinosa-Alonso, B.M. Weckhuysen, I.V. Koptyug, Appl. Catal. Gen. 374 (2010) pp. 126-136.

[31] L. Espinosa-Alonso, A.A. Lysova, P. de Peinder, K.P. de Jong, I.V. Koptyug, B.M. Weckhuysen, J. Am. Chem. Soc. 131 (2009) pp. 6525-6534.

[32] A.J. Sederman, L.F. Gladden, Chem. Eng. Sci. 56 (2001) pp. 2615-2628.

[33] I.V. Koptyug, A.A. Lysova, R.Z. Sagdeev, V.N. Parmon, Catal. Today 126 (2007) pp. 37-43.

[34] L.F. Gladden, M.H.M. Lim, M.D. Mantle, A.J. Sederman, E.H. Stitt, Catal. Today 79-80 (2003) pp. 203-210.

[35] D.. Guilfoyle, P. Mansfield, K.. Packer, J. Magn. Reson. 196997 (1992) pp. 342-358.

[36] A. Haase, J. Frahm, D. Matthaei, W. Hanicke, K.-D. Merboldt, J. Magn. Reson. 196967 (1986) pp. 258-266.

[37] J. Hennig, A. Nauerth, H. Friedburg, Magn. Reson. Med. 3 (1986) pp. 823-833.

[38] D.J. Tyler, M.D. Robson, R.M. Henkelman, I.R. Young, G.M. Bydder, J. Magn. Reson. Imaging 25 (2007) pp. $279-289$.

[39] M. Weiger, K.P. Pruessmann, A.-K. Bracher, S. Köhler, V. Lehmann, U. Wolfram, F. Hennel, V. Rasche, NMR Biomed. 25 (2012) pp. 1144-1151.

[40] A.J. Fagan, N. Nestle, D.J. Lurie, Magn. Reson. Imaging 23 (2005) pp. 317-319.

[41] A.J. Fagan, D.J. Lurie, in:, Annu. Rep. NMR Spectrosc., Elsevier, 2005, pp. 97-140.

[42] S. Gravina, D.G. Cory, J. Magn. Reson. B 104 (1994) pp. 53-61.

[43] S.V. Dvinskikh, K. Szutkowski, I. Furó, J. Magn. Reson. 198 (2009) pp. 146-150. 
RF

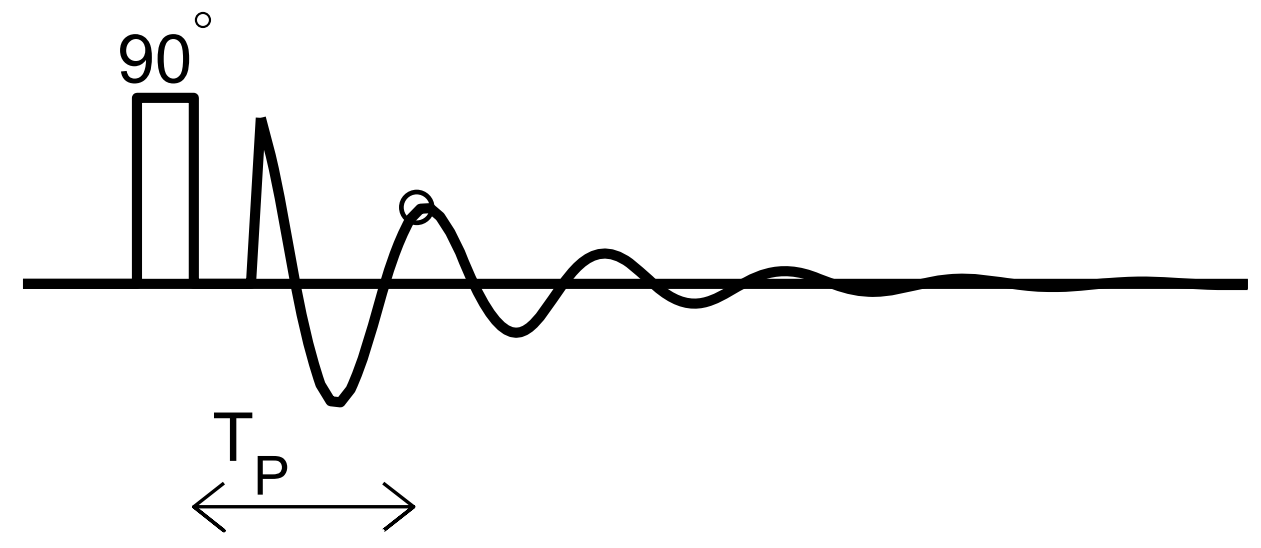

grad
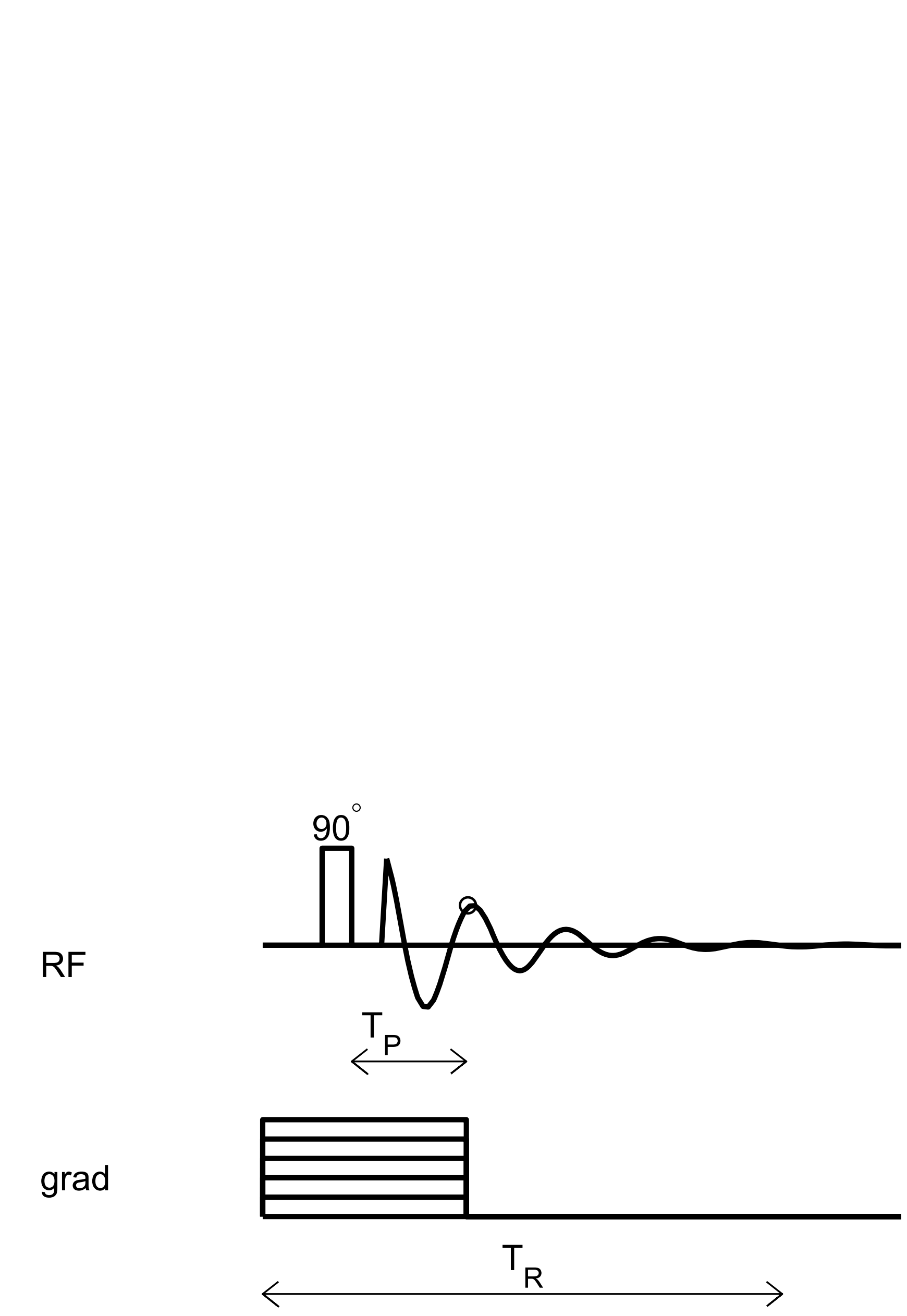

Figure

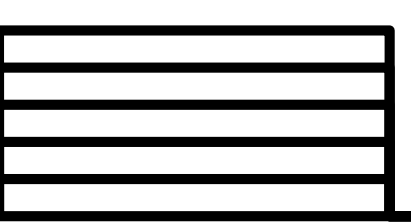




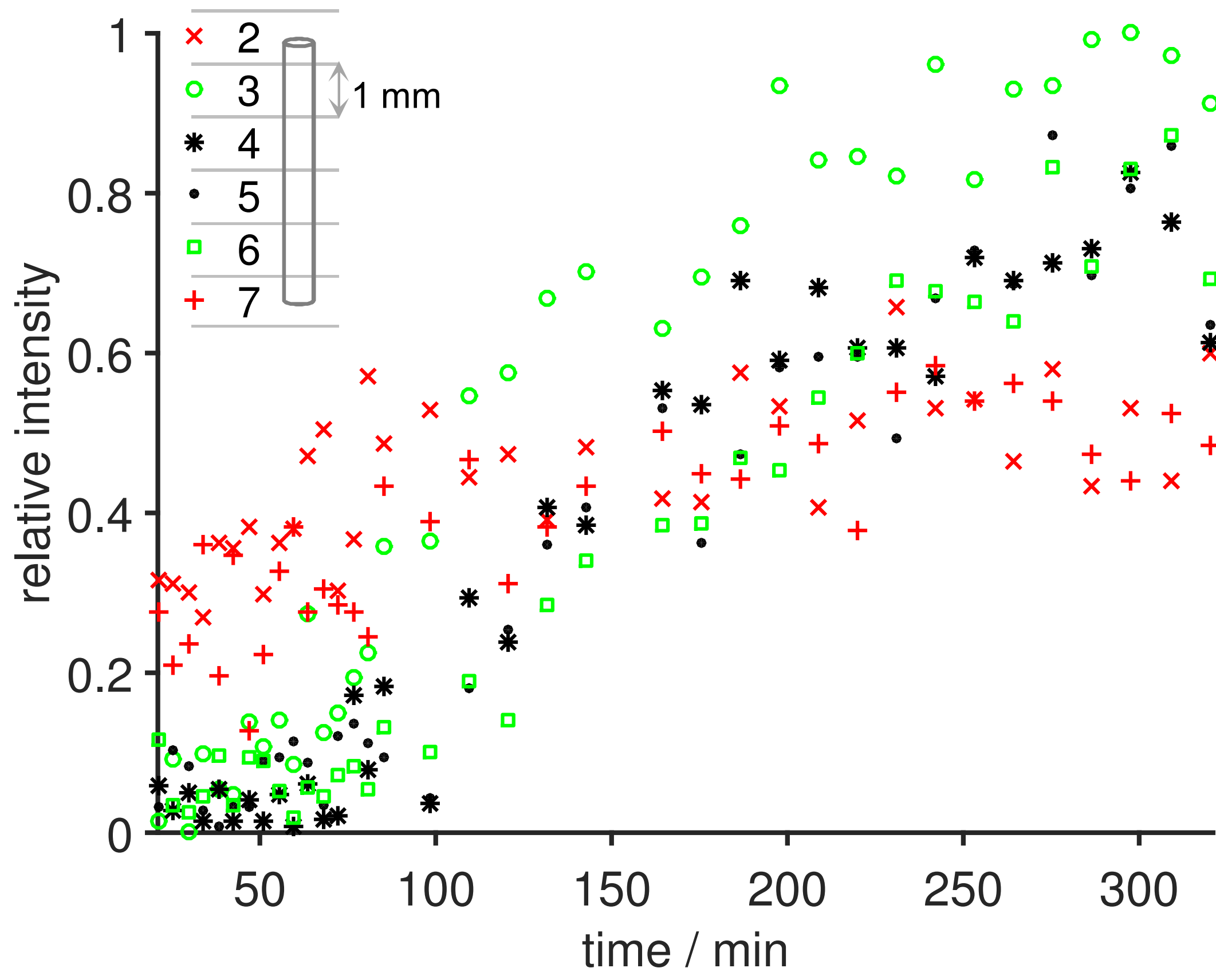


$0.05 \mathrm{M}$

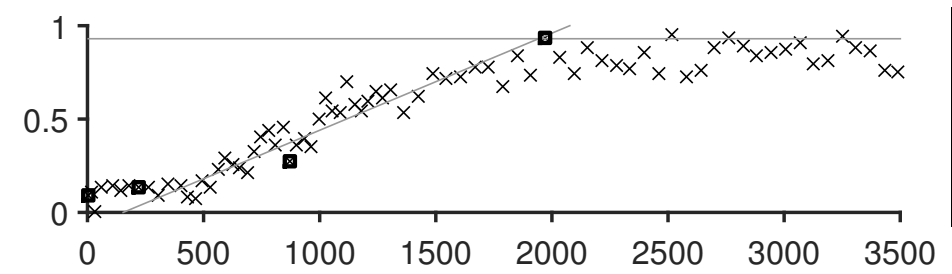

$0.1 \mathrm{M}$

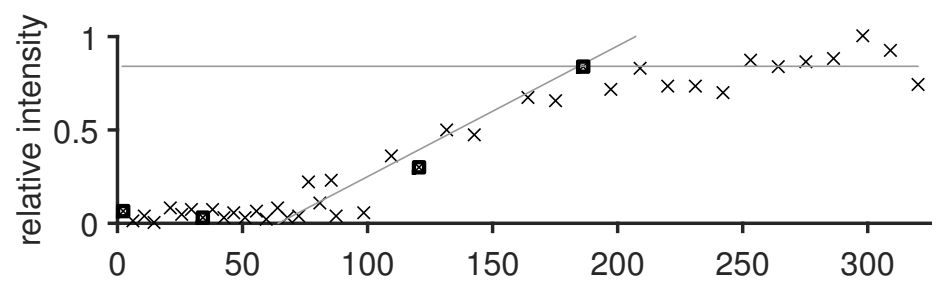

$0.2 \mathrm{M}$

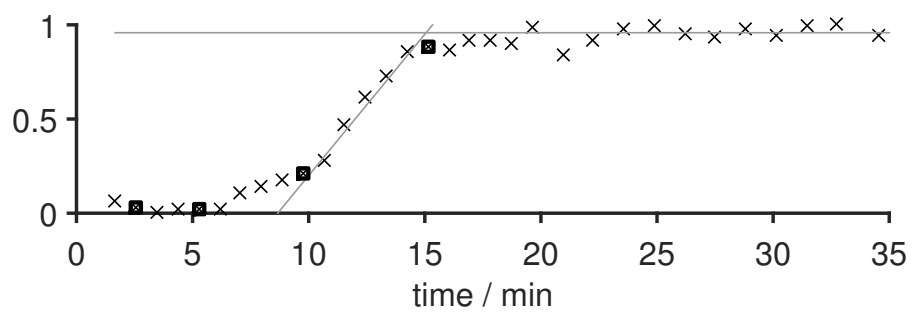

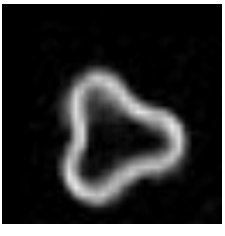
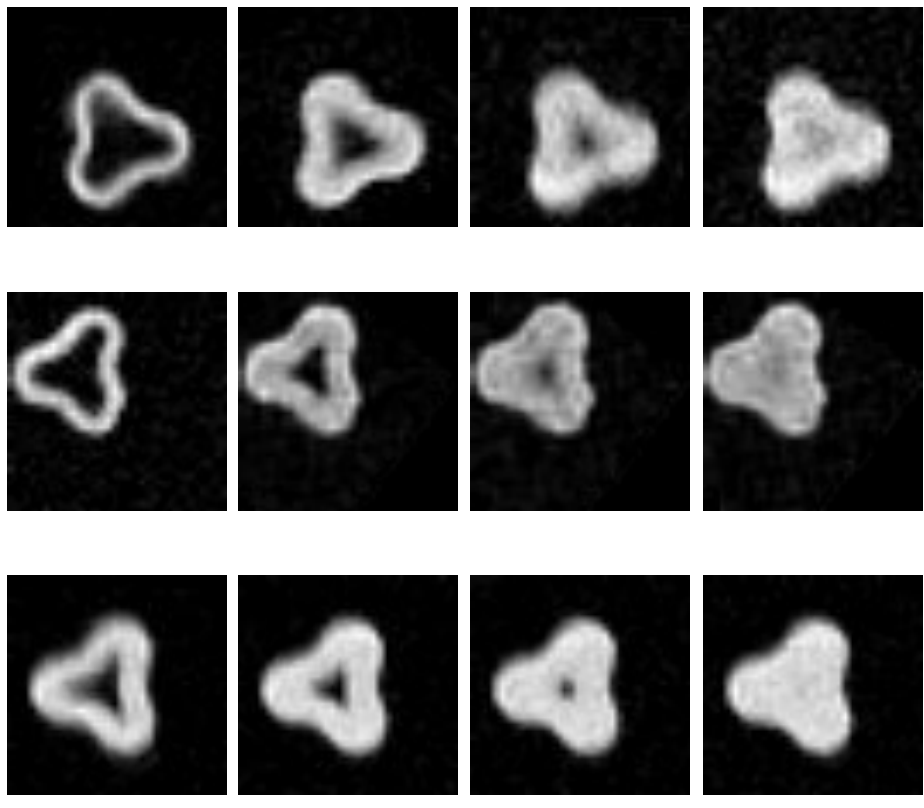


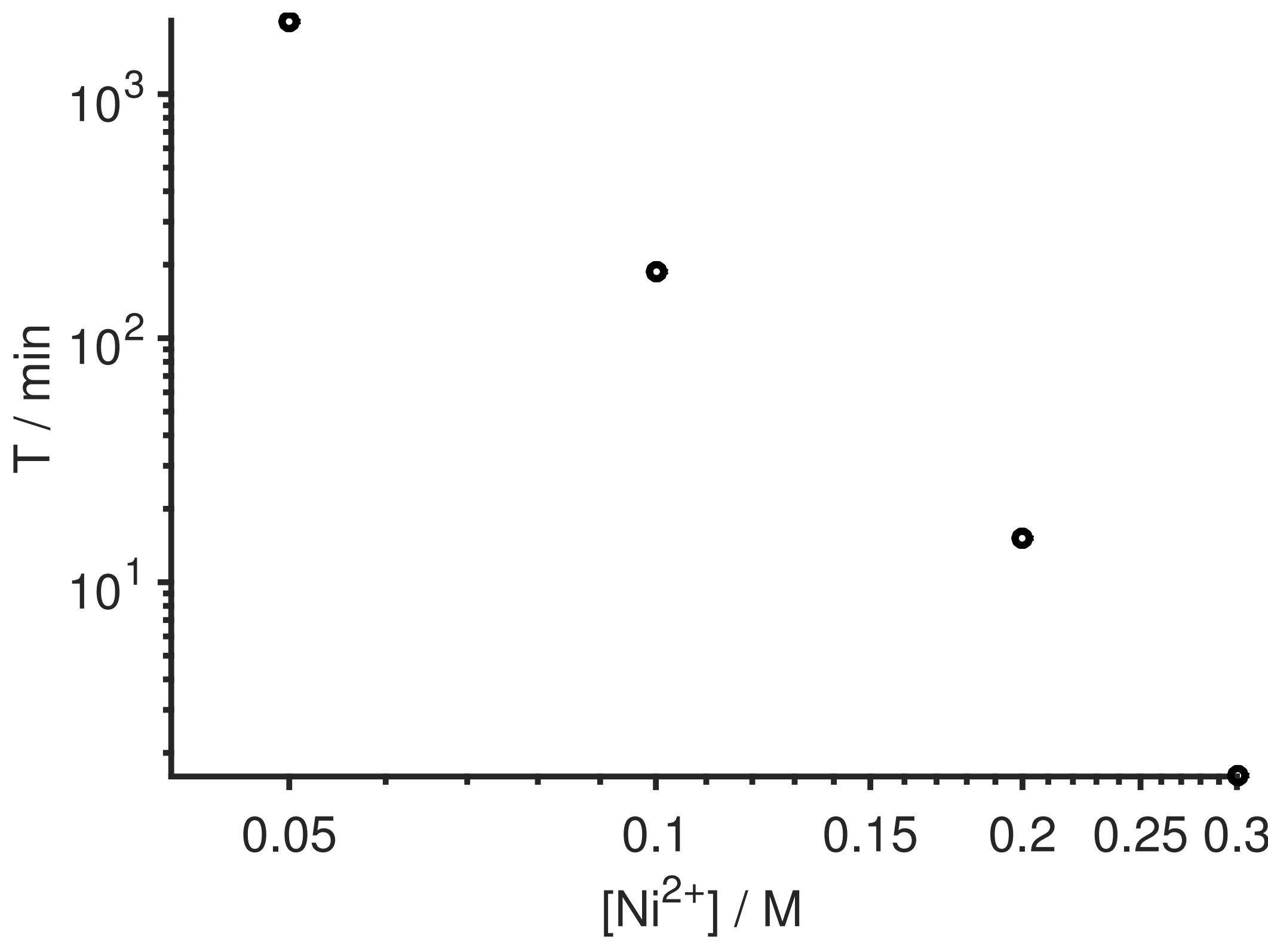

